IZA DP No. 5485

The Threat Effect of Participation in Active Labor Market Programs on Job Search Behavior of Migrants in Germany

Annette Bergemann

Marco Caliendo

Gerard J. van den Berg

Klaus F. Zimmermann

February 2011 


\title{
The Threat Effect of Participation in Active Labor Market Programs on Job Search Behavior of Migrants in Germany
}

\author{
Annette Bergemann \\ University of Mannheim, \\ IFAU-Uppsala and IZA \\ Marco Caliendo \\ $I Z A, D I W$ Berlin and IAB \\ Gerard J. van den Berg \\ University of Mannheim, IFAU-Uppsala, \\ VU University Amsterdam and IZA \\ Klaus F. Zimmermann \\ IZA and University of Bonn
}

Discussion Paper No. 5485

February 2011

\author{
IZA \\ P.O. Box 7240 \\ 53072 Bonn \\ Germany \\ Phone: +49-228-3894-0 \\ Fax: +49-228-3894-180 \\ E-mail: iza@iza.org
}

Any opinions expressed here are those of the author(s) and not those of IZA. Research published in this series may include views on policy, but the institute itself takes no institutional policy positions.

The Institute for the Study of Labor (IZA) in Bonn is a local and virtual international research center and a place of communication between science, politics and business. IZA is an independent nonprofit organization supported by Deutsche Post Foundation. The center is associated with the University of Bonn and offers a stimulating research environment through its international network, workshops and conferences, data service, project support, research visits and doctoral program. IZA engages in (i) original and internationally competitive research in all fields of labor economics, (ii) development of policy concepts, and (iii) dissemination of research results and concepts to the interested public.

IZA Discussion Papers often represent preliminary work and are circulated to encourage discussion. Citation of such a paper should account for its provisional character. A revised version may be available directly from the author. 
IZA Discussion Paper No. 5485

February 2011

\section{ABSTRACT \\ The Threat Effect of Participation in Active Labor Market Programs on Job Search Behavior of Migrants in Germany ${ }^{*}$}

Labor market programs may affect unemployed individuals' behavior before they enroll. Such ex ante effects may differ according to ethnic origin. We apply a novel method that relates self-reported perceived treatment rates and job search behavioral outcomes, such as the reservation wage or search intensity, to each other. We compare German native workers with migrants with a Turkish origin or Central and Eastern European (including Russian) background. Job search theory is used to derive theoretical predictions. We examine the omnibus ex ante effect of the German ALMP system, using the novel IZA Evaluation Data Set, which includes self-reported assessments of the variables of interest as well as an unusually detailed amount of information on behavior, attitudes and past outcomes. We find that the ex ante threat effect on the reservation wage and search effort varies considerably among the groups considered.

JEL Classification: J64, J61, C21, D83, D84

Keywords: immigrants, policy evaluation, reservation wage, search effort, expectations, unemployment duration, program evaluation, active labor market policy

Corresponding author:

Annette Bergemann

Department of Economics

University of Mannheim

L7, 3-5

68131 Mannheim

Germany

E-mail: annette.bergemann@uni-mannheim.de

\footnotetext{
* We thank Olof Åslund, Corrado Giulietti and two anonymous Referees for their comments and suggestions. The IAB (Nuremberg) kindly gave us permission to use the administrative data. Caliendo thanks the German Research Foundation (DFG) for financial support of project CA 829/1-1.
} 


\section{Introduction}

Migrants are often disadvantaged with respect to their labor market outcomes. In Germany the unemployment rate of foreign born men was $11.8 \%$ in 2008 , whereas only $6.8 \%$ of native born men were unemployed. For women the figures are similar at $13.1 \%$ vs. $6.8 \%$ (see OECD, 2010). Past research has shown that differences in employment and earnings between natives and migrants persist, even when controlling for individual characteristics, such as education and age (Algan et al., 2010).

Active labor market policy programs (ALMP) are common tools to improve the labor market outcomes of the unemployed. Potentially, these programs could be particularly helpful for unemployed migrants. Migrants may lack skills specific to the national labor market, and these skills might be easily transferred with the help of labor market policies such as training programs.

ALMP can have ex ante and ex post effects. Evaluation studies typically focus on ex post effects, i.e. on the effect of actual participation. However, ex ante effects, i.e. the effects that occur before participation, may also exert a large effect on unemployment durations. If individuals expect large benefits from a treatment then they may postpone their job search until after the treatment. In this case the ex ante effect is negative, and the average realized unemployment durations of participants and non-participants may be larger than in the absence of the program. Knowledge of ex ante effects is thus an important input for the evaluation of the program and for the assessment of possible modifications of the program. For example, if the ex post effect of having been trained on the exit rate to work is positive, whereas the ex ante effect on this rate is negative, then this may suggest that the program is best offered early on during the unemployment spell.

Ex ante effects require individuals to have some knowledge about the existence of ALMP and about the process leading to participation. The ALMP participation probability is a determinant of the optimal job search strategy and will affect the outcome of interest. Consider, for example, a training program that upgrades skills for a certain profession. Knowledge of the rate that an individual can participate in such a program can be valuable for the individual. If an individual finds out that her individual rate is high then it becomes attractive for the individual to reduce her search effort as participation could lead to higher wages.

In this paper we investigate whether migrants and natives react similarly to the expectation of participating in an ALMP, and whether different types of migrants (as captured by the region of origin) react similarly or not. There are a number of reasons why the migrant status may affect ex ante effects. First, ex ante effects are affected by the extent to which individuals enjoy the participation experience itself, which may depend on the composition of the program. Second, the effects depend on the degree of familiarization 
with the services provided by the employment office and with the baseline expectations about the extent to which the state is perceived as a helpful or as a threatening institution. Some types of migrants may not be aware of the existence of a program at all. Finally, the magnitude of the ex ante effect depends on the magnitude of the ex post effect, so differences in ex ante effects between different types of unemployed may be due to differences in ex post effects. Notice that we do not aim to distinguish formally between these possible explanations. The latter primarily serves as a motivation for why differences may exist. In order to put the results into perspective, we also examine whether natives and migrants have the same job search strategies in terms of search effort and reservation wage values. Any differences in the ex ante effects between the different types of unemployed could help to fine tune the allocation of ALMP and, thus, could help reduce the labor market disadvantages of migrants.

Some bodies of empirical work are relevant for the present study. Evaluation studies of ex post effects by migrant status provide heterogeneous results. ALMP are partly successful and partly ineffective. In rare cases they even seem to be harmful ex post. However, an important lesson from these studies is that migrants are often affected differently by ALMP compared to natives, giving additional emphasis to the importance of our approach to investigate the ex ante effects of ALMP separately. German studies that distinguish between natives and migrants mainly focus on welfare recipients. Huber et al. (2009) evaluate three different types of welfare to work programs and find positive effects of these programs for natives but not for migrants. Aldashev et al. (2010) evaluate short-term training schemes. They estimate positive effects for aptitude tests that are larger for migrants than for natives, and positive effects for short-term skill provision that are especially large for female immigrants. Surprisingly, they find that job search training is generally ineffective and even has a negative effect for female immigrants. Caliendo and Künn (2011) analyze the effects of start-up subsidies for the unemployed and show that both natives and migrants benefit from participation. However, they find higher effects for natives in terms of employment probabilities and income.

There are very few studies on ex ante effects, and they only consider averages of treated individuals rather than specific subgroups like migrants. Black et al. (2003) use locally randomized assignment of treatment status to examine empirically whether this affects the voluntary inflow into unemployment insurance (UI) benefits. Here, the treatment regime starts right after entering the UI regime. Abbring and Van den Berg (2005) show that if the moment of treatment has a random element, if the observed treatment and labor market outcomes are duration variables, and if there is randomized variation in the treatment intensity, then identification of ex ante effects still requires a semi-parametric model structure and absence of anticipation of the moment of treatment (that is, no anticipation beyond what is captured in the treatment assignment equation; see Rosholm and Svarer, 
2008, for an application). De Giorgi (2005) and Van den Berg, Bozio and Costa Dias (2008) use a policy discontinuity in time to study the effect of a treatment at a six-month unemployment duration on the probability of finding work before six months. Specifically, they compare a situation where individuals in the inflow are aware of the policy to a situation where the policy regime has not yet been introduced. Lalive, Van Ours and Zweimüller (2005) observe whether and when unemployed individuals receive advance warnings about the timing of future treatments. By viewing such warnings as treatments themselves, they can apply the semi-parametric timing-of-events framework of Abbring and Van den Berg (2003) to study their effect.

Our approach builds on the study by Van den Berg, Bergemann and Caliendo (2009) that develops and applies a novel general method to identify ex ante effects. Specifically, they identify ex ante effects of the comprehensive German package of active labor market policy by using self-reported variables of unemployed workers in a panel survey. The unemployed are asked about their perceived probability of being treated in future periods, and they are also asked about their current optimal job search strategy, notably their current reservation wage and their current search effort. All things equal, the expectation of a future event that changes the individual's expected present value should have an effect on the reservation wage or, in general, change the current search effort. They find that the ex ante effect on the reservation wage and search effort are negative and positive, respectively. This means that individuals try to prevent program participation by accepting worse jobs and searching harder than they would do if the programs were absent. They conjecture that this is due to a large extent to individuals disliking the actual participation experience.

Van den Berg, Bergemann and Caliendo (2009) use information from the first survey wave of the IZA Evaluation Data Set (see Caliendo et al., 2011, for details). This is an ongoing data collection process in which an inflow sample of unemployed in Germany is followed over time. They use information from the first survey wave. The survey interviews were held in late 2007 and early 2008 with individuals who had recently become unemployed. Respondents answered an extensive set of questions inter alia about their search behavior, reservation wages, previous employment experience, and expectations about program participation.

Similar to Van den Berg, Bergemann and Caliendo (2009), we use the first wave of the IZA Evaluation Data Set. To some extent we use matching in order to estimate the effect of different participation expectations on the reservation wage and the search effort. The matching approach is well-suited to dealing with individual heterogeneity. The data contain a number of self-reported personality and behavioral assessments and individual past labor market outcomes, which allow for a rich set of conditioning variables in the matching procedure. However, migrants with specific countries of origin constitute small subsamples of the full sample, which is why we frequently resort to regression methods. 
The paper has the following structure. Section 2 introduces the job search model on which we build our empirical approach. This model allows individuals to receive utility or disutility from participation in ALMP for reasons other than their effect on labor market outcomes. The data source, the variables used and the definition of migrants are described in Section 3. Section 4 presents the estimation results and Section 5 concludes.

\section{The job search model}

This section summarizes the job search model developed in Van den Berg, Bergemann and Caliendo (2009). In this model the unemployed search sequentially for a job. For a given level of search effort $s$, job offers arrive at a certain rate $\lambda s$. Offers are random drawings from a wage offer distribution $F(w)$. If an offer arrives, the individual must decide whether to accept the wage offer (and keep it forever) or reject it and continue searching at least until the next offer arrives. The individual receives benefits $b$ while unemployed and incurs search costs $c(s)$, which depend on the search effort level. The aim of the individual is to maximize the expected present value of income or utility over an infinite horizon. The optimal search strategy can then be described by the reservation wage $\phi$, giving the minimal acceptable wage offer and an optimal level of search effort $s$.

Program participation is then introduced into this basic job search model. ${ }^{1}$ An individual that has not been treated enters at a specific rate $\eta \geq 0$ into treatment. What actually matters is the perception of individuals about this entrance rate. For convenience, however, we do not distinguish in the text between the perceived rate and the actual treatment rate. Treatment can have an effect on the job finding rate parameter $\lambda$ and/or the wage offer distribution $F(w)$ and the individual is aware of these effects. Concerning treatment, however, the individual does not know the exact moment of treatment, only the rate at which it occurs.

The expected present value without treatment is $R$. With treatment, the expected present value changes to $R_{p}$. The total gain $G$ due to treatment can be described by $G=R_{p}-R-\gamma$, where $\gamma$ captures the direct costs of treatment. These costs can be positive or negative, depending on whether the individual dislikes or likes the treatment. Similarly, the treatment effect $R_{p}-R$ due to changes in the labor market position can also be positive or negative.

In this new setting the reservation wage $\phi$ and the optimal search effort level $s$ depend on the total gains $G$ of the treatment and on the rate $\eta$ at which the treatment occurs. In order to make this explicit, we write $\phi(\eta, G)$ and $s(\eta, G)$. Ex ante effects can then be described by the difference in the reservation wage $\phi$ and the optimal search effort level

\footnotetext{
${ }^{1}$ The main insights are robust with respect to the model assumptions; see the discussion in Van den Berg, Bergemann and Caliendo (2009).
} 
$s$ that arise if we compare a world without treatment, $(\eta=0$ and $G=0)$ with a world with treatment $\left(\eta=\eta_{0}\right.$ and parameter values $\lambda_{p}$ and $F_{p}$ leading to $\left.G=G_{0}\right)$, i.e. by the difference $\phi\left(\eta_{0}, G_{0}\right)-\phi(0,0)$ and $s\left(\eta_{0}, G_{0}\right)-s(0,0)$.

Van den Berg, Bergemann and Caliendo (2009) show that if the total gain is positive and treatment occurs with a positive rate $(G>0$ and $\eta>0)$, then the ex ante effect on the reservation wage $\phi$ is positive, whilst the effect on the optimal search effort level $s$ is negative. As a results, individuals become more choosy and search less extensively. Both effects reduce the transition rate from unemployment to employment. Similarly, if the gains become negative $(G<0)$ and the treatment rate is positive $(\eta>0)$, then the effect on the reservation wage will be negative $\left(\phi\left(\eta_{0}, G_{0}\right)-\phi(0,0)<0\right)$ and on the search effort level positive $\left(s\left(\eta_{0}, G_{0}\right)-s(0,0)>0\right)$. Consequently, if we compare the reservation wage (search effort level) of similar individuals, where one group report a certain value $\eta>0$ with the reservation wage (search effort level) of another group that report a value of $\eta=0$, one is able to draw conclusion on the sign of the total gain of treatment $G$. Thus, the empirical signs of $d \phi / d \eta$ and $d s / d \eta$ can be used to infer whether $G \gtrless 0$. If the empirical signs of $d \phi / d \eta$ and $d s / d \eta$ are zero then there are no ex ante effects, and it can be concluded that $G=0$, so either the program is ineffective, or the program is beneficial but the individual dislikes the treatment itself.

The ex ante effects may be heterogeneous. The extent to which the treatment entry rate influences the optimal job search strategy reflects the effect of treatment on the expected present value. Simultaneously, model determinants that lead to a high rate of moving from unemployment to employment reduce the ex ante effects. Formally, the derivatives $d \phi / d \eta$ and $d s / d \eta$ depend on all the other model determinants, which means that the effect of the treatment entry rate $\eta$ on the reservation wage $\phi$ and on the optimal search effort level $s$ interacts with all other model determinants, leading to heterogeneous ex ante effects. Consequently, the matching method is particularly well-suited to determining ex ante effects, as it allows for effect heterogeneity. Moreover, matching does not impose functional form restrictions and it is explicitly clear about the weighting procedure used to estimate average treatment effects (see also Section 4). However, adequate application of matching requires a sufficiently large sample size. Migrants of specific origins may constitute small samples, so we frequently resort to regression methods where we estimate interaction effects to capture effect heterogeneity.

\section{Data}

In the empirical analysis we estimate ex ante effects for recently unemployed workers of the comprehensive German package of active labor market policies, for both native Germans and migrants separately. The most prominent ALMP in Germany are short training pro- 
grams and job search assistance schemes. However, start-up subsidies for the unemployed, job creation programs, long-term (re-)training programs and wage subsidies for jobs in the private sector are of quite considerable size as well (see Eichhorst and Zimmermann, 2007, or Bernhard et al., 2008, for recent overviews). In Germany, as in other European countries, case workers have a large influence on the (timing of the) participation of an unemployed worker in ALMP. Recently unemployed individuals are typically assigned to job search assistance programs or training programs. Long-term unemployed individuals are more often assigned to employment programs, consisting of either wage subsidy programs for jobs in the private sector or job creation schemes.

The data we use are from the IZA Evaluation Data Set. As explained in Section 1, this survey data set targets an inflow sample into unemployment from June 2007 to May 2008. The key feature of the data set is that individuals are interviewed shortly after they become unemployed and are asked a variety of non-standard questions about attitudes and expectations (see Caliendo et al., 2011, for details). The sampling is restricted to individuals who are 16 to 54 years old and who receive or are eligible to receive unemployment benefits under the German Social Code III. From the monthly unemployment inflows of approximately 206,000 individuals in the administrative records ${ }^{2}$, a $9 \%$ random sample is drawn which constitutes the gross sample. Out of this gross sample representative samples of approximately 1,450 individuals are interviewed each month, so that after one year 12 monthly cohorts are gathered.

For the first wave 17,396 interviews were conducted and individuals were interviewed about two months after becoming unemployed. We restrict our analysis to individuals who are still unemployed and are actively searching for a job. That is, we exclude individuals who have already found a job, are participating in a program or are not searching for other reasons. ${ }^{3}$ This leaves us with a preliminary sample of 8,612 individuals, from which we further exclude the lowest and highest percentile of the reported hourly reservation wage and the reported benefit level as well as individuals with missing values for any key variables. The final results is a sample of 7,913 individuals.

Throughout the paper we use a broad definition for migrants and individuals with migration background (called migrants henceforth). We define an individual as a migrant if the individual is either born abroad, or not in possession of a German passport, or with either a father or a mother who was born abroad. With this definition we basically cover first and second generation migrants. As migrants themselves cannot be expected to be a homogenous group with respect to their labor market behavior, we differentiate between

\footnotetext{
${ }^{2}$ Administrative records are based on the "Integrated Labour Market Biographies" of the Institute for Employment Research (IAB), containing relevant register data from four sources: employment history, unemployment support recipience, participation in active labor market programs, and job seeker history.

${ }^{3}$ Of these three categories, program participation is by far the smallest.
} 
major immigration groups. We distinguish between individuals originating from Central and Eastern Europe/former Yugoslavia, Russia and Turkey. We compare the results found for these migration groups with those of the native Germans. Note that although Germany in the 1960s also experienced a major inflow of Italians, our sample of Italians is too small to consider them a separate group. Instead, we remove the migrants from the other parts of Europe, America, Africa and Asia from our data, and the resulting sample consists of 7,147 individuals.

Table 1 reports some descriptive statistics. Migrants are on average either younger or have the same age as natives (30 to 36 years vs. 36 years). Russians and migrants from Central and Eastern Europe/former Yugoslavia have been staying on average longer in Germany than migrants from Turkey (12 to 13 years vs. 10 years). Migrants tend to live predominantly in West Germany (84\%-93\% vs. 63\%), are more often married (47\%-54\% vs. $38 \%)$ and have more children than natives ( $35 \%-51 \%$ vs. $31 \%$ have children, $0.51-0.89$ vs. 0.48 on average). In addition, the share of unemployment benefit recipients among the group of migrants is lower than among the group of native Germans (73\%-77\% vs. $79 \%$ ). The educational background of migrants varies a lot. Compared to $25 \%$ of native Germans, who have a high school degree, $32 \%$ of migrants from Central and Eastern Europe/former Yugoslavia also have one, whereas this is true of only $17 \%$ of Turkish and $18 \%$ of Russian migrants. Similarly, the previous labor market history in the group of migrants is very diverse. Individuals from Central and Eastern Europe/former Yugoslavia and Russia experience fewer months of unemployment (measured relative to the years since the 18th birthday) than natives (0.65-0.71 vs. 0.83 months), whereas migrants with a Turkish background are more often unemployed than natives (0.89 months). At the same time, however, all migrant groups had fewer previous employment months than natives (again measured relative to the years since the 18 th birthday, $6.12-7.89$ vs. 8.45 months). It is surprising that Russians and the Central and Eastern Europeans/former Yugoslavians have simultaneously shorter unemployment and employment spells, even when age is controlled for. One reason could be that this group of migrants spends more time in education and military service.

Individuals are also asked questions regarding their "locus of control", which is a generalized expectancy about internal versus external control of reinforcement (Rotter, 1966). Whereas individuals whose external locus of control personality trait dominates believe that everything that happens is beyond their control, people with an internal locus of control are confident that outcomes are contingent on their decisions and behavior. ${ }^{4}$ Natives

\footnotetext{
${ }^{4}$ Locus of control is measured by a set of statements to which individuals could reply on a scale of "1" (I do not agree at all) to "7" (I agree fully), e.g., "How my life takes course is entirely dependent on me" or "Success is gained through hard work". We sum up the positive answers and build a single dummy variable if the answers exceed a certain threshold.
} 
do report an average of 5.04 with respect to their locus of control, whereas it is lower for Russians (4.87) and people from Central Eastern Europe/former Yugoslavia (4.95) and Turkey (4.81).

The key variable for our analysis, the entry rate into treatment $\eta$, is measured by the answer to the question how likely it is that ALMP participation occurs conditional on remaining unemployed in the next three months. This explicitly merges all ALMP measures (the main ALMP for short-term unemployed workers are training, job search assistance, and subsidized work). The answers range from 0 ("very unlikely") to 10 ("very likely"). For the analysis we construct a binary measure by grouping $0-4$ into the category " $\eta$-low" and 5-10 into " $\eta$-high". The search effort $s$ is operationalized as the number of search channels used where the maximum number is $10 .^{5}$ This is in line with e.g. Van den Berg and Van der Klaauw (2006) and references therein who also use this outcome as an indicator of search effort. On average, $57 \%$ of native Germans find it highly likely to participate in a program of ALMP (see Table 2). The probability is higher for migrants. Note that the Turkish most often report that it is likely they will participate in an ALMP (69\%), whereas Russians (63\%) and unemployed migrants from Central and Eastern Europe/former Yugoslavia $(61 \%)$ are more similar to natives in that respect. Major differences in the average values of the variables describing the search strategies only exist between the native Germans and the migrants with a Turkish background. The average reservation wage and the average number of search channels of native Germans are $€ 6.89 /$ hour and 5.12 channels, whereas Turkish migrants have on average a higher reservation wage (€7.35) and a smaller number of search channels (4.75), despite the fact that they are, for example, less educated than the average native German. Russians and Central and Eastern Europeans/former Yugoslavians have an average reservation wage of $€ 6.72$ Euro and $€ 7.02$ respectively, and use on average 4.92 and 5.23 search channels.

\section{Empirical Analysis}

As a first step we conduct a simple regression analysis of the logarithm of the reservation wage $(\log \phi)$ and the number of search channels $(s)$ on the expected participation probability $\eta$. We include a large set of additional explanatory variables, for example,

\footnotetext{
${ }^{5}$ Individuals were asked the following questions, where multiple entries were allowed: "What have you done in order to find an apprenticeship or employment? Have you searched... 1: through job advertisements in the newspaper, 2: by personally advertising as a job seeker, 3: through a job information system, 4: through contact with acquaintances, relatives, other private contacts, 5: through an agent from the employment agency, 6: through internet research, 7: through a private agent with agency voucher, 8: through a private agent without agency voucher, 9: through blind application at companies 10: other, 11: nothing of its kind." We take the sum of all answers as the number of search channels.
} 
years since migration as a percentage of age, individual past labor market history, benefit level, education, regional indicators, marital status, number of children, age, means of communications, and month of entry in unemployment. For second-generation immigrants, years since migration is set to zero, as for natives. Additionally we control for personality traits such as locus of control, openness, conscientiousness, extraversion and neuroticism which have proven to be important in recent labor market research (see e.g. Borghans, Duckworth, Heckman, and Ter Weel, 2008). We pool all individuals independently of their origin. However, we introduce dummy variables for the different migration groups as well as interaction terms that combine the migration background and $\eta$ in order to accomplish our goal to investigate whether there are differences in search strategies and differences in the ex-ante effects.

The regression results on the determinants of the reservation wage in Table 3 confirm the descriptive results that Turkish migrants have a higher reservation wage than all other groups. The dummy on Turkish origin is positive and highly significant (10\%). Furthermore, the results suggest that native Germans reduce their reservation wage in case they belong to the " $\eta$-high" category by $2.8 \%$. The coefficients on the other interaction terms are slightly larger, however, not significant.

With respect to search channels we find some differences between the different groups of origins. Russians seem to have a somewhat lower search effort level than the other groups (the coefficient on Russians is negative, but only significant at the $10 \%$ level.) Most importantly for our analysis of the ex-ante effects, the OLS estimates suggest that native Germans, Central and Eastern Europeans/former Yugoslavians and Russians significantly increase their search effort when they expect to participate in an ALMP. Only individuals with a Turkish background do not change their search effort level in response to their expected extent of participation in ALMP. This is in contrast to all other groups considered here. We conclude that the Turkish migrants are quite different in this respect from natives and the two other migration groups (Central and Eastern Europeans/former Yugoslavians and Russians). Notice that years since migration does not have a significant effect. One explanation for this is that this variable contrasts second-generation immigrants and natives on the one side to first-generation migrants on the other side. We return to this in the concluding section of the paper.

As a next step, we proceed by using propensity score matching (introduced by Rosenbaum and Rubin, 1983; see Caliendo and Kopeinig, 2008, Imbens and Wooldridge, 2008, and Blundell and Costa Dias, 2009, for recent overviews) in order to estimate the average "treatment-on-the-treated" effect (ATET), where of course in our case the "treatment" is the entry rate into ALMP participation. As we need a reasonable sample size for matching, we merge Central and Eastern Europeans/former Yugoslavians and Russians, and call this group henceforth CEER. Despite matching being able to handle heterogeneity of treatment 
effects, we omit Turkish migrants, as they seem to react so very differently. ${ }^{6}$ Note that the treatment consists in being in the " $\eta$-high" group as compared to being in the " $\eta$-low" group. Thus, we regard a high subjective probability of participating in an ALMP conditional on staying unemployed as the treatment. After estimating the propensity score for the probability of being in the " $\eta$-high" category (we use the same rich set of conditioning variables as in the OLS regressions, see Table 4 for the score estimates and Figure 1 for the score distribution), we perform Kernel-matching ${ }^{7}$ in order to obtain ATET estimates. The estimation procedure is conducted separately for migrants and natives. In addition, we also want to investigate whether there are differences in the search behavior between natives and migrants, conditional on them being in a certain " $\eta$ " category. In this case we interpret being a migrant as a treatment vs. being a native German. One can think of this approach as a thought experiment which answers the question: What would happen to the reservation wage and the search intensity of a native German with the average characteristics of a migrant and who would become a migrant. Here, we omit the "years since migration" as it would be heavily related to the outcome measure.

Let us turn to the estimation results for the matching analyses. For both native Germans and CEER, we find that the ex ante effects on the reservation wage are negative and on the search effort are positive, respectively (see Table 5). Having the perspective of otherwise going into a program of ALMP, native Germans and CEER migrants are willing to accept worse jobs by lowering their reservation wage. Natives with a high $\eta$ lower their reservation wage by $3.0 \%$ and CEER migrants by $3.9 \%$, but the coefficient is not significant at conventional levels ( $p$-value: 0.12 ). Both migrants and natives with a high $\eta$ also search significantly harder, and the effect is larger for migrants (0.46 or $9 \%$ more channels) than natives ( 0.22 or $4.3 \%$ more channels). This shows that both migrants and natives with high $\eta$ actively try to prevent participation.

We now address the question whether there are differences between migrants and native Germans within the " $\eta$-low" or " $\eta$-high" group, respectively. The estimates of ATET are also presented in Table 5, in which we do not find significant differences for the " $\eta$-low" groups. This means that migrants from CEER who are part of the " $\eta$-low" group have the same average reservation wage and average search effort as similar native Germans. Furthermore, we are not able to find significant differences in the average reservation wages for the " $\eta$-high" groups. However, we do find that CEER migrants increase the search effort level even more than similar native Germans in view of a likely participation in ALMP.

\footnotetext{
${ }^{6}$ Indeed, when including Turkish migrants the results seem to be partly driven by their inclusion. At the same time the group of Turkish migrants is too small in order to use matching for them alone. Due to insufficient overlap we would need to discard $7 \%$ of all "treated".

${ }^{7}$ For the kernel matching procedure, we use an Epanechnikov kernel with a bandwidth of 0.06 and impose the common support condition based on the "MinMax" criterion.
} 
Thus, CEER migrants try to prevent participation in ALMP even harder than native Germans by searching more intensively.

Both sets of matching results are in full agreement with the OLS results. With this in mind, we may return to the OLS estimates for Turkish migrants. Those results suggest that Turkish migrants try to prevent participation by reducing the reservation wage by a similar amount to native Germans. However, note that the initial level of the reservation wage of Turkish migrants is higher than the one of similar natives. At the same time, Turkish migrants do not show signs of adjustment in their search effort. From this we conclude that migrants with a Turkish background struggle less than native Germans and CEER migrants to prevent participation in ALMP. ${ }^{8}$

In addition, we conduct a separate matching analysis for Russians and for Central and Eastern Europeans/former Yugoslavians. As the OLS results already indicate, we find some differences between these two groups with regard to the search effort level. However, further research is required to investigate any differences between these groups because the current sample precludes an in-depth investigation; whereas with additional waves of the panel, we will be able to take advantage of multiple observations per individual and exploit the information in realized outcomes.

The analysis naturally raises the question where the differences between native Germans and migrants might originate from, and why there are differences between migrants of different origins.

One potential explanation could be that individuals of different origins interpret questions in the interview in different ways. In one sense, we can rule out this possibility, because in many cases native speakers were used when interviewing migrants. In particular, Turkish speakers were used to interview Turkish respondents, and Russian speakers were used for respondents who were fluent in Russian but not in German. What we cannot rule out is that respondents from certain regions of origin have difficulties with the concept of a reservation wage as such because they expect to be able to bargain over the wage and other job characteristics. Another potential explanation is that the groups differ with respect to the type of jobs they expect and that the differences in reservation wage reflect compensating wage differentials. However, these explanations only explain different levels of the reservation wage. As a first-order approximation, it should not be able to explain differences in ex-ante effects.

Yet another potential explanation for the differences in the ex ante effects is that individuals of different origins have different degrees of awareness of the program (see De Graaf-Zijl, Van den Berg and Heyma, 2011). However, in our data only very few migrants (and native Germans) reported not to know about ALMP programs. Therefore, we can reject this possibility as well.

\footnotetext{
${ }^{8}$ The matching estimates for Turkish, although based on very few observations, support these results.
} 
If differences in the information sets are excluded, then, according to the theoretical model (see Section 2), the differences in the ex ante effects either derive from differences in the ex post treatment effects due to changes in the labor market position or from differences in direct costs of treatment. At the current state of research, we can only speculate which of these aspects might play a role here. The evidence on ex-post treatment effects is insufficient in order to state with some certainty that they are (partly) responsible for the heterogeneity in the ex ante effects; but naturally they remain a potential candidate for the explanation.

One could, however, also suspect that the direct costs of treatment differ between the different nationalities. For example, the higher search intensity of CEER migrants to prevent participation could originate from a stronger dislike of governmental intervention compared to native Germans and Turkish individuals or from the special involvement of case workers, which makes search cheaper.

In contrast to natives and, even more so, in contrast to CEER migrants, Turkish individuals do not increase their search intensity if they face participation in ALMP. They either benefit more from participation in ALMP or their direct costs of participation are lower. One supporting aspect why the direct costs of participation could be responsible is related to the higher reservation wages of Turkish individuals compared to other nationalities. The higher reservation wage could reflect that Turkish have a lower nonpecuniary disutility of unemployment (probably due to neighborhood effects of living close to other unemployed individuals). This lower nonpecuniary disutility of unemployment could also transfer to lower costs of participation in ALMP.

\section{Conclusions}

Using a recently developed method to determine ex ante effects of participation in ALMP, this paper uncovers the heterogeneity of these effects according to migrant status in Germany. We find that the search behavior of Turkish migrants is not affected by the probability of future participation in ALMP. There is a moderate threat effect for native Germans, while individuals from Central and Eastern Europe, Russia and former Yugoslavia increase their job search behavior most in order to prevent participation. We speculate that next to differences in the ex post treatment effect, the differences in ex ante effects may be driven by differences in the direct cost of treatment, perhaps derived from a dislike of governmental intervention (for the Central and Eastern Europeans, Russians and former

Yugoslavians) and lower disutility of staying unemployed and participating in a program (Turkish migrants).

Note that prevention of participation is not per se in the interest of society. In order to return to work fast, individuals might accept jobs in which their productivity is not fully 
exploited. Therefore, it is interesting to investigate further the sources of the heterogeneity and to examine realized post-unemployment outcomes. The results of our study suggest that an important group for this consists of migrants from Central and Eastern Europe, Russia, and former Yugoslavia, as this group shows the strongest dislike for ALMP.

Another interesting topic for further research would be to explore differences between first- and second generation migrants. Recent work by Constant et al. (2010a,b) provides evidence that first- and second-generation migrants differ in terms of attitudes towards risk, language skills, and reservation wages. From this one may expect differences in the response to a high perceived probability of ALMP participation as well. Presumably, our explanatory variable capturing years since migration is not able to capture any such generation-specific differences. Moreover, stratifying by generation as well as by region of origin would result in subsamples that are too small to allow for meaningful inference. One would therefore like to have access to a larger sample of migrants from a specific region of origin. Moreover, following Constant et al. (2010a), one may extend the theoretical job-search framework by including behavioral-economic concepts. 


\section{References}

Abbring, J.H. and G.J. van den Berg (2003), "The non-parametric identification of treatment effects in duration models", Econometrica, 71(5), 1491-1517.

Abbring, J.H. and G.J. van den Berg (2005), "Social experiments and instrumental variables with duration outcomes", Working paper 2005:11, IFAU, Uppsala.

Aldashev, A., S.L. Thomsen, and T. Walter (2010), "Short-term training programs for immigrants: Do effects differ from natives and why?", Discussion paper 10-021, ZEW, Mannheim.

Algan, Y., C. Dustmann, A. Glitz, and A. Manning (2010), "The economic situation of first- and second-generation immigrants in France, Germany, and the United Kingdom", Economic Journal, 120(542), F4-F30.

Bernhard, S., K. Hohmeyer, E. Jozwiak, S. Koch, T. Kruppe, G. Stephan and J. Wolff (2008), "Aktive Arbeitsmarktpolitik in Deutschland und ihre Wirkungen", Research report $2 / 2008$, IAB, Nuremberg.

Black, D.A., J.A. Smith, M.C. Berger, and B.J. Noel (2003), "Is the threat of reemployment services more effective than the services themselves? Evidence from random assignment in the UI system", American Economic Review, 93(4), 1313-1327.

Blundell, R. and M. Costa Dias (2009), "Alternative approaches to evaluation in empirical microeconomics", Journal of Human Resources, 44(3), 565-640.

Borghans, L., A.L. Duckworth, J.J. Heckman, and B. ter Weel (2008), "The Economics and Psychology of Personality Traits", Journal of Human Resources, 43(4), 972-1059.

Caliendo, M., A. Falk, L. Kaiser, H. Schneider, A. Uhlendorff, G.J. van den Berg, and K.F. Zimmermann (2011), "The IZA Evaluation Data Set: Towards evidence-based labour policy-making", International Journal of Manpower, forthcoming.

Caliendo, M., and S. Kopeinig (2008), "Some practical guidance for the implementation of propensity score matching", Journal of Economic Surveys, 22(1), 31-72.

Caliendo, M., and S. Künn (2011), "Start-Up Subsidies for the Unemployed: Long-Term Evidence and Effect Heterogeneity", Journal of Public Economics, forthcoming.

Constant, A.F., A. Krause, U. Rinne and K.F. Zimmermann (2010a), "Economic Preferences and Attitudes of the Unemployed: Are Natives and Second Generation Migrants Alike?", IZA Discussion Paper 5380, IZA, Bonn.

Constant, A.F., A. Krause, U. Rinne and K.F. Zimmermann (2010b), "Reservation Wages of First and Second Generation Migrants", IZA Discussion Paper 5396, Bonn. 
De Graaf-Zijl, M., G.J. van den Berg, G., A. Heyma (2011), "Stepping stones for the unemployed: the effect of temporary jobs on the duration until (regular) work", Journal of Population Economics, 24, 107-139.

De Giorgi, G. (2005), "Long term effects of a mandatory multistage program: The New Deal for Young People in the UK", Working paper 05/08, UCL, London.

Eichhorst, W. and K.F. Zimmermann (2007), "And Then There Were Four...How Many (and Which) Measures of Active Labor Market Policy Do We Still Need?", Applied Economics Quarterly, 53(3), 243-272.

Huber, M., M. Lechner, C. Wunsch, and T. Walter (2009), "Do German welfare-to-work programmes reduce welfare and increase work?", Discussion Paper 4090, IZA, Bonn.

Imbens, G.W. and J.M. Wooldridge (2009), "Recent developments in the econometrics of program evaluation", Journal of Economic Literature, 47(1), 5-86.

Lalive, R., J.C. van Ours, and J. Zweimüller (2005), "The effect of benefit sanctions on the duration of unemployment", Journal of the European Economic Association, 3(6), $1386-1417$.

OECD (2010), International Migration Outlook 2010, OECD, Paris.

Rosenbaum, P.R. and D.B. Rubin (1983): "The central role of the propensity score in observational studies for causal effects", Biometrika, 70(1), 41-55.

Rosholm, M. and M. Svarer (2008), "The threat effect of active labour market programmes", Scandinavian Journal of Economics, 110(2), 385-401

Rotter, J.B. (1966), Generalized expectancies for internal versus external control of reinforcement, American Psychological Association, Washington DC.

Van den Berg, G.J. and B. van der Klaauw (2006), "Counseling and monitoring of unemployed workers: Theory and evidence from a controlled social experiment", International Economic Review, 47(3), 895-936.

Van den Berg, G.J., A. Bergemann, and M. Caliendo (2009), "The effect of active labor market programs on not-yet treated unemployed individuals", Journal of the European Economic Association, 7(2-3), 606-616.

Van den Berg, G.J., A. Bozio and M. Costa Dias (2008), "Policy discontinuity and duration outcomes", Working paper, VU University Amsterdam. 
Table 1: Selected Sample Descriptives: Baseline Characteristics for Natives and Migrants

\begin{tabular}{|c|c|c|c|c|}
\hline Variables & Native & Russian & $\begin{array}{r}\text { Central \& Eastern } \\
\text { European/ } \\
\text { Yugoslavian } \\
\end{array}$ & Turkish \\
\hline $\mathrm{N}$ & 6181 & 325 & 432 & 209 \\
\hline West Germany & 0.63 & 0.93 & 0.84 & 0.93 \\
\hline Female & 0.50 & 0.51 & 0.58 & 0.46 \\
\hline German citizenship & 1.00 & 0.93 & 0.74 & 0.50 \\
\hline Years since migration & 0.00 & 12.99 & 12.36 & 9.96 \\
\hline Age & 35.95 & 32.05 & 36.09 & 30.33 \\
\hline Age (17-24 years) & 0.22 & 0.36 & 0.17 & 0.29 \\
\hline Age (25-34 years) & 0.25 & 0.29 & 0.33 & 0.45 \\
\hline Age (35-44 years) & 0.28 & 0.20 & 0.26 & 0.20 \\
\hline Age (45-55 years) & 0.26 & 0.15 & 0.24 & 0.06 \\
\hline Married (or cohabiting) & 0.38 & 0.54 & 0.48 & 0.47 \\
\hline Number of children & 0.48 & 0.73 & 0.51 & 0.89 \\
\hline \multicolumn{5}{|l|}{ Children } \\
\hline No children & 0.69 & 0.56 & 0.65 & 0.49 \\
\hline One child & 0.18 & 0.24 & 0.21 & 0.23 \\
\hline Two (or more) children & 0.13 & 0.20 & 0.13 & 0.28 \\
\hline Locus of Control $(1=$ external, $7=$ internal $)$ & 5.04 & 4.87 & 4.95 & 4.81 \\
\hline Unemployment benefit recipient ( $1=$ yes) & 0.79 & 0.73 & 0.76 & 0.77 \\
\hline Level of UB (missings $=0)$ & 510.84 & 424.39 & 503.87 & 478.29 \\
\hline Level of UB $(\log ($ ben +1$)$, mis $=0)$ & 4.73 & 4.34 & 4.61 & 4.67 \\
\hline \multicolumn{5}{|l|}{ School leaving degree } \\
\hline None, special needs, other & 0.02 & 0.03 & 0.03 & 0.12 \\
\hline Lower secondary school & 0.29 & 0.34 & 0.31 & 0.43 \\
\hline Middle secondary school & 0.44 & 0.45 & 0.33 & 0.28 \\
\hline Specialized upper secondary school & 0.25 & 0.18 & 0.32 & 0.17 \\
\hline \multicolumn{5}{|l|}{ Professional Qualification } \\
\hline None & 0.08 & 0.18 & 0.14 & 0.32 \\
\hline Internal or external professional training & 0.73 & 0.65 & 0.65 & 0.54 \\
\hline Technical college or university degree & 0.19 & 0.17 & 0.21 & 0.14 \\
\hline Months in unemployment (div. by age-18) & 0.83 & 0.65 & 0.71 & 0.89 \\
\hline Months in employment (div. by age-18) & 8.45 & 6.14 & 7.89 & 7.81 \\
\hline \multicolumn{5}{|l|}{ Employment status before unemployment } \\
\hline Employed & 0.65 & 0.59 & 0.69 & 0.66 \\
\hline Subsidized employment & 0.07 & 0.08 & 0.07 & 0.05 \\
\hline School, apprentice, military, etc. & 0.15 & 0.19 & 0.10 & 0.14 \\
\hline Maternity leave & 0.05 & 0.06 & 0.05 & 0.06 \\
\hline Other & 0.08 & 0.08 & 0.09 & 0.09 \\
\hline
\end{tabular}

Source: IZA Evaluation Data Set, own calculations.

Note: All numbers are shares unless stated otherwise. 
Table 2: Perceived Treatment Entry and Search Intensity of Natives and Migrants

\begin{tabular}{lrrrr}
\hline \hline Variables & Native & Russian & $\begin{array}{r}\text { Central \& Eastern } \\
\text { European/ } \\
\text { Yugoslavian }\end{array}$ & Turkish \\
\hline $\mathrm{N}$ & & & 432 & 209 \\
Subjective (overall) probability of treatment & 4.80 & 5.24 & 5.13 & 5.72 \\
participation (0=very low, 10=very high) & & & & \\
& $(3.58)$ & $(3.45)$ & $0.54)$ & $(3.39)$ \\
Participation probability $(\eta \geq 5)$ & 0.57 & 0.63 & 7.02 & 7.35 \\
Reservation wage (in euros) & 6.89 & 6.72 & $(2.25)$ & $(2.09)$ \\
& $(2.32)$ & $(2.04)$ & 5.23 & 4.75 \\
Number of search channels & 5.12 & 4.92 & $(1.67)$ & $(1.65)$ \\
& $(1.67)$ & $(1.61)$ & & \\
\end{tabular}

Source: IZA Evaluation Data Set, own calculations.

Note: All numbers are shares unless stated otherwise; standard deviations in parentheses. 
Table 3: OLS Estimation Results - Reservation Wage and Number of Search Channels

\begin{tabular}{|c|c|c|}
\hline & $\log \phi$ & $s$ \\
\hline \multicolumn{3}{|l|}{ Migration background (Ref.: Natives) } \\
\hline Russians & 0.004 & $-.310^{*}$ \\
\hline Central \& Eastern European, former YU. & -.002 & -.021 \\
\hline Turkish & $0.1^{* * *}$ & -.158 \\
\hline \multicolumn{3}{|l|}{ Migration background $\times$ participation probability } \\
\hline Natives $\times \eta^{H}$ & $-.028^{* * *}$ & $0.231^{* * *}$ \\
\hline Russians $\times \eta^{H}$ & -.039 & $0.505^{* * *}$ \\
\hline Central \& Eastern European, former YU. $\times \eta^{H}$ & -.039 & $0.377^{* *}$ \\
\hline Turkish $\times \eta^{H}$ & -.045 & -.018 \\
\hline West Germany & $0.161^{* * *}$ & $0.145^{* * *}$ \\
\hline Years since migration (divided by age) & -.0002 & 0.135 \\
\hline Female & $-.123^{* * *}$ & 0.019 \\
\hline Married (or cohabiting) & -.007 & $0.139^{* * *}$ \\
\hline \multicolumn{3}{|l|}{ Children (Ref.: No children) } \\
\hline One child & $0.025^{* * *}$ & -.040 \\
\hline Two (or more) children & $0.055^{* * *}$ & $-.234^{* * *}$ \\
\hline Unemployment benefit recipient ( $1=$ yes $)$ & $-.037^{* *}$ & 0.033 \\
\hline Level of unemployment benefits $(\log ($ ben +1$)$, mis $=0)$ & $0.01^{* * *}$ & $0.028^{* *}$ \\
\hline \multicolumn{3}{|l|}{ Age (Ref.: $17-24$ years) } \\
\hline Age (25-34 years) & $0.094^{* * *}$ & $-.151^{* *}$ \\
\hline Age (35-44 years) & $0.149^{* * *}$ & -.028 \\
\hline Age (45-55 years) & $0.153^{* * *}$ & -.074 \\
\hline \multicolumn{3}{|l|}{ School leaving degree } \\
\hline \multicolumn{3}{|l|}{ None, special needs, other (Ref.) } \\
\hline Lower secondary school & $0.064^{* * *}$ & 0.019 \\
\hline Middle secondary school & $0.076^{* * *}$ & 0.161 \\
\hline Specialized upper secondary school & $0.154^{* * *}$ & -.035 \\
\hline \multicolumn{3}{|l|}{ Vocational training } \\
\hline \multicolumn{3}{|l|}{ None (Ref.) } \\
\hline Int. or ext. prof. training, others & $0.067^{* * *}$ & $0.18^{* *}$ \\
\hline Technical college or university degree & $0.214^{* * *}$ & $0.33^{* * *}$ \\
\hline Months in unemployment (div. by age-18) & $-.013^{* * *}$ & -.007 \\
\hline Months in employment (div. by age-18) & $0.001^{*}$ & $0.006^{*}$ \\
\hline \multicolumn{3}{|l|}{ Personality traits } \\
\hline Locus of Control (1 = Internal) & $0.027^{* * *}$ & $-.097^{* *}$ \\
\hline Openness (standardized) & $0.017^{* * *}$ & $0.065^{* * *}$ \\
\hline Conscientiousness (standardized) & -.002 & $0.102^{* * *}$ \\
\hline Extraversion (standardized) & $0.009^{* *}$ & $0.05^{* *}$ \\
\hline Neuroticism (standardized) & $-.012^{* * *}$ & $-.064^{* * *}$ \\
\hline \multicolumn{3}{|l|}{ Father has A-level qualifications? } \\
\hline \multicolumn{3}{|l|}{ Not known (ref.) } \\
\hline Yes & $0.04^{* *}$ & 0.136 \\
\hline No & 0.017 & $0.166^{*}$ \\
\hline \multicolumn{3}{|l|}{ Father employed at age $15 ?$} \\
\hline \multicolumn{3}{|l|}{ Not known or already dead (ref.) } \\
\hline Yes & -.008 & -.090 \\
\hline No & -.0009 & 0.021 \\
\hline \multicolumn{3}{|c|}{ Employment status before Unemployment (Ref.: Employed) } \\
\hline Subsidized employment & -.020 & 0.019 \\
\hline School, apprentice, military, etc. & $-.046^{* * *}$ & -.072 \\
\hline Maternity leave & $-.028^{*}$ & -.066 \\
\hline Other & -.006 & $-.130^{*}$ \\
\hline \multicolumn{3}{|l|}{ Available means of communication: } \\
\hline Landline telephone & $-.020^{*}$ & $-.235^{* * *}$ \\
\hline Personal mobile phone & $0.022^{*}$ & 0.077 \\
\hline Computer & 0.003 & -.040 \\
\hline Printer & -.008 & $0.27^{* * *}$ \\
\hline Internet & $0.033^{* *}$ & 0.155 \\
\hline Email & $0.029^{* *}$ & $0.232^{* * *}$ \\
\hline Observations. & 7,147 & 7,147 \\
\hline Pseudo- $\mathrm{R}^{2}$ & 0.303 & 0.062 \\
\hline
\end{tabular}

Note: Additional control variables used in the estimation: Months of entry into unemployment (June 2007 - April 2008), time between entry and interview (in weeks) and living situation. Full estimation results are available on request by the authors.

$* * * / * * / *$ indicate significance at the $1 \% / 5 \% / 10 \%$-level. 
Table 4: Propensity Score Estimation: General Participation Expectation in ALMP

\begin{tabular}{|c|c|c|c|c|}
\hline & $\begin{array}{l}\text { CEER migr.: } \\
\text { High vs. Low } \eta\end{array}$ & $\begin{array}{c}\text { Natives: } \\
\text { High vs. Low } \eta\end{array}$ & $\begin{array}{l}\text { High } \eta \text { : CEER } \\
\text { vs. Natives }\end{array}$ & $\begin{array}{l}\text { Low } \eta \text { : CEER } \\
\text { vs. Natives }\end{array}$ \\
\hline & $(1)$ & $(2)$ & $(3)$ & $(4)$ \\
\hline West Germany & -.186 & $0.297^{* * *}$ & $1.277^{* * *}$ & $1.728^{* * *}$ \\
\hline Female & 0.209 & $0.153^{* * *}$ & -.053 & -.025 \\
\hline Married (or cohabiting) & $-.336^{*}$ & -.095 & $0.799^{* * *}$ & $1.053^{* * *}$ \\
\hline \multicolumn{5}{|l|}{ Children (Ref.: No children) } \\
\hline One child & 0.087 & -.002 & $0.258^{*}$ & 0.088 \\
\hline Two (or more) children & -.026 & 0.12 & 0.078 & 0.032 \\
\hline Years since migration (divided by age) & -.030 & & & \\
\hline Unemployment benefit recipient ( $1=$ yes) & 0.036 & $0.29^{* *}$ & -.337 & -.142 \\
\hline Level of UB $(\log ($ ben +1$)$, mis $=0)$ & 0.012 & 0.008 & 0.021 & 0.032 \\
\hline \multicolumn{5}{|l|}{ Age (Ref.: $17-24$ years) } \\
\hline Age (25-34 years) & 0.084 & $-.167^{*}$ & $-.320^{* *}$ & $-.475^{* *}$ \\
\hline Age (35-44 years) & 0.209 & $-.198^{* *}$ & $-.911^{* * *}$ & $-1.158^{* * *}$ \\
\hline Age (45-55 years) & -.2123 & $-.373^{* * *}$ & $-1.066^{* * *}$ & $-1.236^{* * *}$ \\
\hline \multicolumn{5}{|l|}{ School leaving degree } \\
\hline \multicolumn{5}{|l|}{ None, special needs, other (Ref.) } \\
\hline Lower secondary school & -.346 & -.101 & -.147 & -.305 \\
\hline Middle secondary school & -.488 & -.251 & -.050 & -.171 \\
\hline Specialized upper secondary school & -.359 & $-.442^{* *}$ & -.016 & -.688 \\
\hline \multicolumn{5}{|l|}{ Vocational training } \\
\hline \multicolumn{5}{|l|}{ None (Ref.) } \\
\hline Int. or ext. prof. training, others & -.346 & 0.023 & $-.624^{* * *}$ & -.204 \\
\hline Technical college or university degree & -.488 & $-.347^{* * *}$ & $-.423^{*}$ & -.157 \\
\hline Months in unemployment (div. by age-18) & $-.200^{* * *}$ & $-.081^{* * *}$ & $-.162^{* * *}$ & -.028 \\
\hline Months in employment (div. by age-18) & -.0002 & -.007 & $-.045^{* * *}$ & $-.066^{* * *}$ \\
\hline \multicolumn{5}{|l|}{ Personality traits } \\
\hline Locus of Control (1=Internal) & -.212 & 0.004 & $-.201^{*}$ & -.075 \\
\hline Openness (standardized) & -.102 & $0.053^{*}$ & $-.250^{* * *}$ & -.094 \\
\hline Conscientiousness (standardized) & -.076 & 0.019 & 0.001 & 0.093 \\
\hline Extraversion (standardized) & 0.105 & -.015 & 0.009 & -.093 \\
\hline Neuroticism (standardized) & 0.124 & -.030 & $0.185^{* * *}$ & 0.038 \\
\hline \multirow{2}{*}{\multicolumn{5}{|c|}{$\begin{array}{l}\text { Father has A-level qualifications? } \\
\text { Not known (ref.) }\end{array}$}} \\
\hline & & & & \\
\hline Yes & 0.252 & -.150 & $0.997^{* * *}$ & 0.476 \\
\hline No & 0.057 & -.033 & 0.199 & -.017 \\
\hline \multicolumn{5}{|l|}{ Father employed at age $15 ?$} \\
\hline \multicolumn{5}{|l|}{ Not known or already dead (ref.) } \\
\hline Yes & -.101 & 0.071 & -.286 & 0.016 \\
\hline No & -.163 & 0.226 & -.126 & 0.488 \\
\hline \multicolumn{5}{|c|}{ Employment status before UE (Ref.: Employed) } \\
\hline Subsidized employment & 0.019 & -.048 & 0.131 & 0.146 \\
\hline School, apprentice, military, etc. & 0.05 & $0.193^{* *}$ & $-.555^{* * *}$ & $-.484^{*}$ \\
\hline Maternity leave & -.017 & 0.085 & $-.570^{* *}$ & -.442 \\
\hline Other & -.123 & -.110 & -.192 & -.148 \\
\hline Rent & $0.332^{*}$ & -.070 & $0.592^{* * *}$ & 0.193 \\
\hline Subletting & -.037 & -.011 & 0.325 & 0.335 \\
\hline Other & 0.01 & $-.681^{*}$ & 0.465 & -.326 \\
\hline \multicolumn{5}{|l|}{ Available communication (non-exclusive) } \\
\hline Landline telephone & -.391 & -.146 & 0.206 & 0.391 \\
\hline Personal mobile phone & -.030 & 0.007 & $-.698^{* * *}$ & $-.625^{* * *}$ \\
\hline Computer & 0.397 & 0.08 & 0.073 & 0.004 \\
\hline Printer & 0.062 & -.098 & -.277 & $-.428^{*}$ \\
\hline Internet & -.138 & 0.104 & 0.246 & 0.311 \\
\hline Email & -.045 & -.068 & $-.498^{* *}$ & -.427 \\
\hline Observations. & 757 & 6181 & 3980 & 2954 \\
\hline Pseudo-R ${ }^{2}$ & 0.066 & 0.032 & 0.142 & 0.14 \\
\hline
\end{tabular}

Note: Estimations are done using a logit model. CEER stands for Central and Eastern Europe, Russia and former Yugoslavia. Additional control variables used: month of entry into unemployment and time between entry and interview. $* * * / * * / *$ indicate significance at the $1 \% / 5 \% / 10 \%$ level. 
Table 5: Matching Results: Reservation Wage and Number of Search Channels

\begin{tabular}{|c|c|c|c|c|c|c|c|c|c|}
\hline Comparison & $\begin{array}{r}\text { Outcome } \\
\text { variable }\end{array}$ & ATET & s.e. & t-value & "Treated" & "Untreated" & Off support & $\begin{array}{l}\text { Bias after } \\
\text { matching }\end{array}$ & $\begin{array}{l}\text { Median bias } \\
\text { after matching }\end{array}$ \\
\hline \multirow[t]{2}{*}{ CEER migr.: High vs. Low $\eta$} & $\log \phi$ & -0.039 & 0.023 & -1.649 & 466 & 291 & 9 & 2.296 & 2.098 \\
\hline & $s$ & 0.458 & 0.133 & 3.42 & 466 & 291 & 9 & 2.296 & 2.098 \\
\hline \multirow[t]{2}{*}{ Natives: High vs. Low $\eta$} & $\log \phi$ & -0.030 & 0.008 & -3.758 & 3516 & 2665 & 0 & 0.627 & 0.482 \\
\hline & $s$ & 0.220 & 0.043 & 5.068 & 3516 & 2665 & 0 & 0.627 & 0.482 \\
\hline \multirow[t]{2}{*}{ High $\eta$ : CEER vs. Natives } & $\log \phi$ & -0.009 & 0.018 & -0.512 & 466 & 3513 & 1 & 1.908 & 1.643 \\
\hline & $s$ & 0.152 & 0.089 & 1.695 & 466 & 3513 & 1 & 1.908 & 1.643 \\
\hline \multirow[t]{2}{*}{ Low $\eta$ : CEER vs. Natives } & $\log \phi$ & 0.009 & 0.021 & 0.398 & 291 & 2663 & 5 & 2.041 & 1.387 \\
\hline & $s$ & -0.144 & 0.112 & -1.286 & 291 & 2663 & 5 & 2.041 & 1.387 \\
\hline
\end{tabular}

Notes: CEER stands for Central and Eastern Europe, Russia and former Yugoslavia. We apply kernel (Epanechnikov) matching with common support; for the bandwidth we follow Silverman's rule-of-thumb and use 0.06. Standard errors are based on 1000 bootstrap replications. Extensive sensitivity analyses are available on request by the authors. Results are not sensitive to the kernel or bandwidth choice. Estimations are done using the PSMATCH2 package by Leuven and Sianesi.

Matching quality: we report the mean (median) standardized bias after matching. In addition, we show the number of individuals in each group ("treated" and "untreated") and the number of individuals lost due to missing common support (off support). 
Figure 1: Propensity Score Distributions for the Different Comparisons

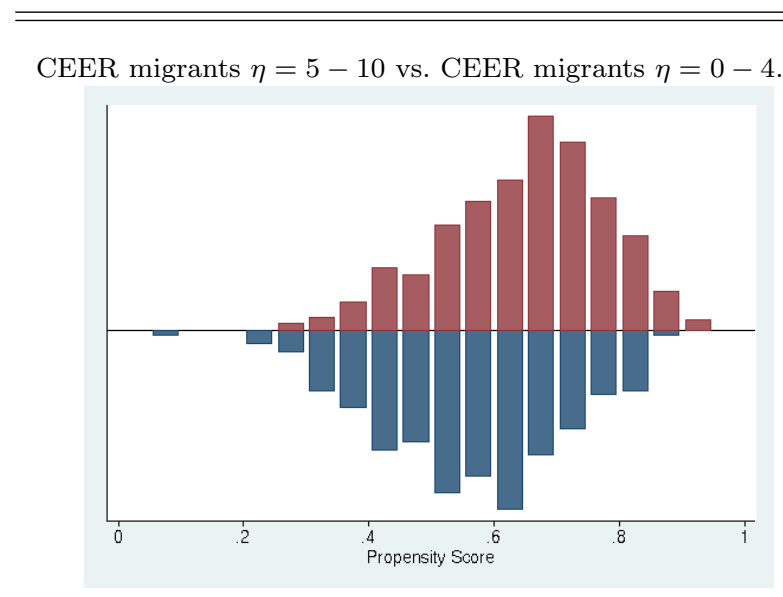

Natives $\eta=5-10$ vs. Natives $\eta=0-4$

CEER migrants $\eta=5-10$ vs. Natives $\eta=5-10$.

CEER migrants $\eta=0-4$ vs. Natives $\eta=0-4$
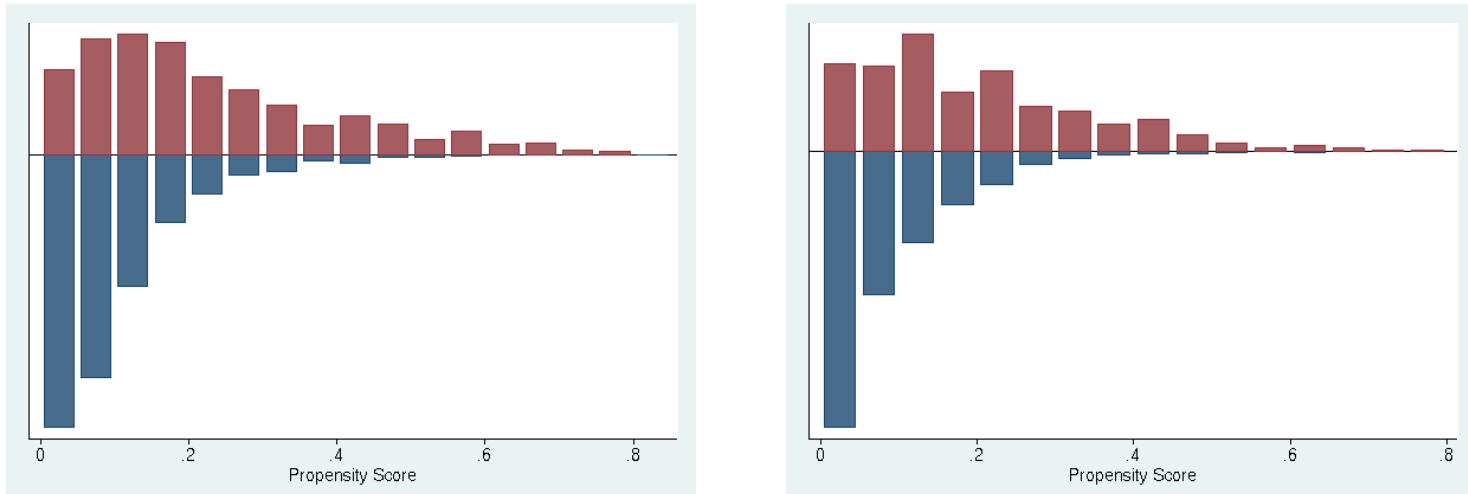

Note: Propensity score estimation results are in Table 4 . Individuals with high participation expectations $(\eta=5-10)$ are depicted in the upper half, individuals with low participation expectations $(\eta=0-4)$ in the lower half. Migrants from Central and Eastern Europe, Russia and former Yugoslavia (CEER) are depicted in the upper half, natives in the lower half of the second row. 